\title{
LA POSIBILIDAD DE TODA PERSONA DE DISPONER DE UNA VIVIENDA DIGNA: UN OBJETIVO DE VALOR CONSTITUCIONAL EN EL DEREGHO FRANGÉS*
}

\author{
THE POSSIBILITY FOR EVERTONE TO HAVE ACCESS \\ TO ADEQUATE HOUSING: AN OBJECTIVE \\ OF CONSTITUTIONAL VALUE IN FRENCH LAW
}

\section{José Sebastián KURLAT AIMAR**}

RESUMEN: El texto de la Constitución francesa de 1958 y los textos a los que ella envía no mencionan expresamente un derecho a la vivienda. Sin embargo, ello no fue obstáculo para que el juez constitucional consagre un objetivo de valor constitucional: la posibilidad de toda persona de disponer de una vivienda digna. Este mecanismo, propio al derecho galo, se integra de manera sui generis a las reglas y principios de referencia del control de constitucionalidad - el llamado bloque de constitucionalidad-. El presente texto se interroga sobre la naturaleza y alcances de dicho objetivo constitucional. En un primer momento, es analizada la consagración del mismo. En segundo término, nos concentramos sobre su vocación primera: encuadrar la legislación. Finalmente, son estudiadas sus principales consecuencias contenciosas. Ciertamente, el pretor encuentra este objetivo constitucional con anclaje en los párrafos 10 y 11 del Preámbulo de 1946
ABSTRACT: The text of the French Constitution of 1958 and the texts to which it refers do not expressly mention a right to housing. However, this did not prevent the constitutional judge to consegrate an objective of constitutional value: the possibility for everyone to have access to adequate housing. This sui generis mechanism integrates the constitutional rules and principles - the so-called constitutional block - This text questions the nature and scope of this constitutional objective. Firstly, we will analyze its consecration. Secondly, we will focus on its primary vocation: framing the legislation. Finally, we will study its main contentious consequences. Indeed, the judge finds this constitutional objective within the $10^{\text {th }}$ and $11^{\text {th }}$ paragraph of the Preamble of 1946 and in the Principle of the dignity of the person. At the same time, the objective of constitutional value operates in a teleological way, for the future, resulting in limited progressiveness and a possible penalty of the unconstitutional omission. Its implementation involves certain tensions with Property rights and other rights and freedoms.

* Artículo recibido el 28 de julio de 2017 y aceptado para su publicación el 6 de octubre de 2017.

** ORCID: 0000-0002-0670-5154. Doctor en derecho, Universidad de Buenos Aires. Docteur en Droit, Université París 1 Panthéon-Sorbonne.

Boletín Mexicano de Derecho Comparado, nueva serie, año XLX, núm. 152, mayo-agosto de 2018, pp. 599-626.

Esta obra está bajo una Licencia Creative Commons Atribución-NoComercial-SinDerivar 4.0 Internacional, IIJ-UNAM. 
y en el principio de la dignidad de la persona. A su vez, el objetivo de valor constitucional opera de manera teleológica, para el futuro, dando lugar a una progresividad limitada y a una posible sanción de la omisión inconstitucional. Su puesta en marcha implica ciertas tensiones con el derecho de propiedad y con otros derechos y libertades.

Palabras clave: vivienda, encuadramiento constitucional, objetivo de valor constitucional, Francia, derechos sociales.

Keywords: housing, constitutional framework, objective of constitutional law, France, social rights.

SUMARIO: I. Introducción. II. El reconocimiento de un objetivo de valor constitucional. III. Un mecanismo para encuadrar la legislación. IV. El objetivo de valor constitucional de la vivienda digna en el contencioso constitucional. V. Conclusiones.

\section{INTRODUCGIÓN}

1. “...para cada derecho, nos preocupamos no solamente por afirmar sus principios sino por definir los medios concretos de su realización”. ${ }^{1}$ Esta aseveración de una obra clásica del derecho constitucional francés de la posguerra revela un sentido profundo para el objeto de la presente contribución. La categoría de los derechos sociales, en efecto, muestra que resulta inútil consagrar los derechos liberales civiles y políticos sin considerar la pertenencia del individuo a la comunidad social. ${ }^{2}$

1 Duverger, Maurice, Droit constitutionnel et institutions politiques [Derecho Constitucional e instituciones políticas], 4a. ed., París, PUF, 1959, p. 358.

2 Gicquel, Jean y Gicquel, Jean-Eric, Droit constitutionnel et institutions politiques [Derecho Constitucional e instituciones políticas], 22a. ed., París, Domat, 2008, p. 97; Bossuyt, Marc, "La distinction juridique entre les droits civils et politiques et les droits économiques, sociaux et culturels" [La distinción jurídica entre los derechos civiles y políticos y los derechos económicos, sociales y culturales], Revue des Droits de l'Homme, vol. VIII, núm. 4, 1975, p. 783; Drago, Roland, "La protection des droits économiques et sociaux en France" [La protección de los derechos económicos y sociales en Francia], en Drago, Roland et al., Vers une protection efficace de droits économiques et sociaux? [¿Hacia una protección eficaz de los derechos económicos y sociales?], Bruselas, Bruylant, 1973, pp. 37-47; Le Pourhiet, Anne-Marie, Droit Constitutionnel [Derecho Constitucional], 2a. ed., París, Económica, 2008, p. 138.

Esta obra está bajo una Licencia Creative Commons

Atribución-NoComercial-SinDerivar 4.0 Internacional, IIJ-UNAM.

Boletín Mexicano de Derecho Comparado, núm. 152, pp. 599-626. 
2. Es históricamente interesante tener en cuenta que la mayoría de los derechos sociales constitucionales en Francia figuran en el Preámbulo de la Constitución de 1946. Por una suerte de mecanismo de "muñeca rusa", el Preámbulo de la Constitución de 1958 remite a este texto que sirve a su turno de norma de referencia en ocasión del ejercicio del control de constitucionalidad, integrando el así llamado bloque de constitucionalidad. ${ }^{3}$ Debe notarse que ninguna mención a la vivienda figura en el mismo.

3. El derecho constitucional galo, pese a esta ausencia normativa, desarrolló un objetivo de valor constitucional. Esta noción actúa como un vector que canaliza una protección constitucional en determinada materia y produce consecuencias jurídicas en un contencioso de la norma. Tal es entonces la definición de los términos de este trabajo: ausencia de derecho constitucional subjetivo y presencia de un objetivo de valor constitucional.

4. Por otra parte, quisiéramos someramente en este estudio introductorio abrir un poco el tema y plantearnos el interrogante de saber si el derecho a la vivienda puede ser considerado un derecho fundamental. La cuestión se presenta toda vez que es la ley la que instituyó un derecho "oponible" a la vivienda. ${ }^{4}$ ¿Pueden existir derechos fundamentales consagrados por la vía legislativa y ausentes de la Constitución?

5. Nuestra postura, brevemente, y dejando para otra ocasión un desarrollo más extenso de la misma, es que sí, efectivamente. La asociación entre derechos fundamentales y derechos únicamente constitucionales es, a nuestro entender, una mala compresión de la fundamentalidad de los derechos concentrada exclusivamente en una aparente jerarquía normativa. ${ }^{5}$

6. Si reconocemos, en primer lugar, que los derechos fundamentales tienen una dimensión ética y, al mismo tiempo, admitimos que operan como una objetividad normativa de manera ontológica, arribaremos a la conclusión de que un derecho fundamental puede ser reconocido por operadores

3 Favoreu, Louis, "El bloque de la constitucionalidad", Revista del Centro de Estudios Constitucionales, núm. 5, 1990, pp. 45-68.

4 Ley núm. 2007-290 del 5 de marzo de 2007 instituyendo un derecho oponible a la vivienda y versando sobre diversas medidas a favor de la cohesión social precitada.

5 Picard, Etienne, "L'émergence des droits fondamentaux en France" [La emergencia de los derechos fundamentales en Francia], AfDA, núm. especial "Les droits fondamentaux: une nouvelle catégorie juridique?” [Los derechos fundamentales: ¿Una nueva categoría jurídica?], 1998, pp. 6-42. 
jurídicos diversos y variados. No sólo por el constituyente, sino también por el legislador e, inclusive, por el juez. ${ }^{6}$

7. De esta manera, trataremos de lanzarnos hacia una reflexión sobre la vivienda en el derecho hexagonal limitándonos al campo constitucional. Nuestro perímetro dejará afuera las consideraciones infra constitucionales y las propias al derecho internacional, tanto general como europeo. Los límites de nuestro estudio estarán, pues, determinados por el análisis de la consagración de este objetivo constitucional (I), su función tendiente a encuadrar la legislación (II) y sus implicancias contenciosas (III).

\section{EL RECONOCIMIENTO DE UN OBJETIVO DE VALOR CONSTITUCIONAL}

8. Este objetivo fue establecido en dos etapas. En un primer momento, el Consejo Constitucional, en su decisión número 90-274 DC del 29 de mayo de 1990, reconoce que la promoción de la vivienda de las "personas desfavorecidas" responde a una "exigencia de interés nacional" sin precisar su valor constitucional. ${ }^{7}$ Seguidamente, en su decisión número 95-359

6 Picard, Etienne, "Droits fondamentaux" [Derechos fundamentales], Dictionnaire de la culture juridique [Diccionario de la cultura jurídica], París, PUF, 2003, pp. 544-549.

7 La decisión que precisa que las acciones llevadas adelante para garantizar la vivienda a personas desfavorecidas responden a una exigencia de "interés nacional" versa sobre la libre administración de las colectividades territoriales, en el marco de la ley núm. 90-449 del 31 de mayo de 1990 tendiente a la puesta en marcha del derecho a la vivienda. En la especie, la institución de un ingreso mínimo de inserción se tradujo, en un retorno a los mecanismos anteriormente aplicados de distribución de competencias y financiamientos. "En esta decisión, el Consejo Constitucional afirma sin ambigüedad la facultad del legislador de instaurar en las colectividades territoriales ciertas categorías de gastos obligatorios. Esta facultad no es sin embargo ilimitada: por un lado, el legislador debe señalar con precisión el valor y el alcance de las obligaciones así impuestas, exigencia que excluye todo reenvío importante al poder reglamentario. Por otra parte, la instauración de las contribuciones obligatorias no debe desconocer la competencia propia de las colectividades territoriales ni obstaculizar su libre administración. En resumen, la misma debe tener una justificación real y un alcance limitado”. Véase nota de Prétot, Xavier, Droit sanit. et soc., vol. 26, núm. 4, octubre-diciembre de 1990, p. 714. Así: “...pertenece al legislador la facultad de definir las competencias respectivas del Estado y de las colectividades territoriales en lo que concierne las acciones a llevar adelante para promover la vivienda de las personas desfavorecidas que responde a una exigencia de interés nacional”. Cffr. cons. núm. 14, decisión núm. 90-274 DC del 29 de mayo de 1990.

Esta obra está bajo una Licencia Creative Commons

Atribución-NoComercial-SinDerivar 4.0 Internacional, IIJ-UNAM.

Boletín Mexicano de Derecho Comparado, núm. 152, pp. 599-626. 
DC del 19 de enero de 1995, la jurisdicción constitucional consagró el objetivo de valor constitucional relativo a la posibilidad de "toda persona" (aspecto cuantitativo) de disponer de una "vivienda digna" (aspecto cualitativo). Mientras que en 1990 la exigencia de interés nacional concernía únicamente a las "personas desfavorecidas", ${ }^{8}$ esta decisión tendió a la inclusión de las personas de ingresos modestos y no exclusivamente a las personas en situación de calle o indigentes. En lo que respecta al aspecto cualitativo, la noción de "vivienda digna" fue acusada de imprecisa por los sesenta diputados que demandaron ante el Consejo Constitucional la inconstitucionalidad de la ley relativa a la solidaridad y a la renovación urbana que dio lugar a la decisión número 2000-436 DC. La definición de vivienda digna considerada por el juez como "suficientemente precisa" es la de "una vivienda que no presente riesgos manifiestos que puedan atentar contra la seguridad física o la salud y dotada de elementos conforme a los usos habitacionales". ${ }^{9}$ Incluso cuando se trata de una definición vaga, ella permite asociar la "vivienda" a un verdadero "hábitat" y no a un simple refugio. Por otra parte, una definición más precisa hubiera tornado dificil la concreción del objetivo de valor constitucional. Sin embargo, esta indeterminación fue identificada por una parte de la doctrina como un factor que torna menos vasto el campo de aplicación de este objetivo constitucional en comparación con los restantes. ${ }^{10}$

9. El Consejo Constitucional dedujo este objetivo de un cúmulo de tres referencias textuales que se superponen entre sí. ${ }^{11}$ Por un lado, los párrafos 10 y 11 del Preámbulo de 1946 (A), por otro, el principio de la "dignidad" de la persona $(\mathrm{B})$.

8 Véase cons. núm. 13, decisión núm. 90-274 DC del 29 de mayo de 1990 precitada.

9 Cons. núm. 55 de la decisión núm. 2000-436 DC del 7 de diciembre de 2000.

10 Por ejemplo: "A propósito, en primer lugar, de las palabras 'toda persona', podemos preguntarnos si ellas implican que los discapacitados puedan disponer de viviendas especialmente adaptadas". Cffr. De Montalivet, Pierre, Les objectifs à valeur constitutionnelle [Los objetivos de valor constitucional] (tesis), Univ. Panthéon-Assas (París II), 2004, p. 329 .

En cuanto a la "vivienda", ella es definida por Gérard Cornu en Vocabulaire furidique [Vocabulario jurídico], París, PUF, 2011, p. 144, como: "Inmueble construido sirviendo de habitación principal (o secundaria) de una persona o de una familia que la ocupa a título de propietario, de inquilino o de ocupante".

11 Nota de Jorion, Benoît, AfJDA, 20 de junio de 1995, p. 457.

Esta obra está bajo una Licencia Creative Commons Atribución-NoComercial-SinDerivar 4.0 Internacional, IIJ-UNAM. Boletín Mexicano de Derecho Comparado, núm. 152, pp. 599-626. 


\section{La referencia a los párrafos 10 y 11 del Preámbulo de 1946}

10. Siguiendo la sugestión de los requirentes y sin dificultades, el Consejo Constitucional se refiere expresamente a los párrafos 10 y 11 del Preámbulo de 1946. ${ }^{12}$ Así, según el alto tribunal, asegurar al individuo y a las familias las "condiciones necesarias para su desarrollo" (párrafo 10) y garantizar la "protección de la salud", "la seguridad material" y "el descanso" (párrafo 11) implica necesariamente disponer de una vivienda.

11. En efecto, sobre los principios afirmados por el Preámbulo en 1946, el Consejo Constitucional reconoció progresivamente la mayoría de los derechos económicos y sociales de valor constitucional: derecho al trabajo (5o. párrafo), derechos sindicales y derecho de huelga (6o. párrafo), principio de participación de los trabajadores en la determinación de las condiciones del empleo y en la gestión de la empresa (8o párrafo) y derecho a la salud y a la seguridad (párrafo 11). La filosofía de la totalidad del Preámbulo tiende a insertar en la continuidad constitucional la proclamación de principios políticos, económicos y sociales particularmente necesarios en nuestros tiempos para completar las libertades y derechos fundamentales de la Declaración de los Derechos del Hombre y el Ciudadano del 26 de agosto de 1789. Se trató de una reforma de las instituciones al servicio de una concepción renovada de la democracia, “...menos formal, más abierta a las realidades económicas y sociales, más preocupada por la solidaridad en el seno de la colectividad” (7). Es la “... síntesis entre los principios del liberalismo político que postulan la preservación del ciudadano contra los abusos estatales y la llegada de la democracia económica y social que implica, a la inversa, la intervención de las personas públicas". ${ }^{13}$

12. Sin embargo, "...ningún derecho de esta naturaleza había sido objeto de una creación ex nihilo por el Consejo Constitucional [quien efec-

12 Véase cons. núm. 4 y 5, decisión precitada. También llama la atención que los requirentes habían invocado el principio que surge del segundo párrafo del Preámbulo (derecho a una vida familiar normal) en los términos de la decisión núm. 325-93 DC del 13 de agosto de 1993 relativa a la ley sobre el encuadramiento de la inmigración. La demanda introductoria de instancia mostraba la imposibilidad de ejercer este derecho sin acceso a una vivienda. Sin embargo, el Consejo Constitucional no se sirvió de esta jurisprudencia.

13 Cfr. Conac, Gérard et al., Le Préambule de la Constitution de 1946. Histoire, analyse et commentaires [El Preámbulo de la Constitución de 1946. Historia, análisis y comentarios], París, Dalloz, 2001, p. 48.

Esta obra está bajo una Licencia Creative Commons

Atribución-NoComercial-SinDerivar 4.0 Internacional, IIJ-UNAM.

Boletín Mexicano de Derecho Comparado, núm. 152, pp. 599-626. 
tuando] referencias casi sistemáticas al Preámbulo y a la Declaración [había evitado] pronunciarse sobre la constitucionalidad de los nuevos derechos no inscriptos en alguno de estos textos". ${ }^{14}$ En particular, los llamados derechos-acreencia no figuran sino en textos internacionales, los que el Consejo Constitucional no integra al bloque de constitucionalidad. Corresponde tener en cuenta, sin embargo, que lo que el alto Consejo mencionó no es un verdadero derecho sino una posibilidad. Consagrar un auténtico derecho a la vivienda hubiera sido mucho más percutiente y el juez se abstuvo de ello. Yendo más allá de lo que los requirentes habían demandado, esta decisión se funda igualmente y de manera acumulativa en el principio de valor constitucional de la "salvaguarda de la dignidad de la persona". ${ }^{15}$

\section{La referencia al principio de la "dignidad de la persona"}

13. Esta filiación entre la posibilidad de disponer de una vivienda digna y el principio de la dignidad de la persona muestra que la misma implica la referencia a condiciones adecuadas de existencia. El Consejo ya había consagrado, en ocasión de las leyes relativas a la bioética, en 1994, la salvaguarda de la "dignidad de la persona contra toda forma de servilismo y de degradación". ${ }^{16}$

14 Zitouni, François, "Le Conseil Constitutionnel et le logement des plus démunis" [El Consejo Constitucional y la vivienda de los más desposeídos], LPA, 12 de enero de 1996, núm. 6, p. 16.

15 Véase cons. núm. 6, decisión precitada.

16 G. C., decisión núm. 94-343 DG del 27 de julio de 1994. Este fallo declara conformes a la Constitución dos leyes relativas al respeto del cuerpo humano y a la donación y utilización de productos del cuerpo humano, a la asistencia médica para la procreación y al diagnóstico prenatal. Esta decisión se funda en la frase preliminar del Preámbulo de la Constitución de 1946 que proclama: "Tras la victoria de los pueblos libres sobre los regímenes que pretendieron sojuzgar y degradar la persona humana, el pueblo francés proclama de nuevo que cualquier ser humano, sin distinción de raza, religión o creencias, posee derechos inalienables y sagrados". La dignidad no figura expresamente en ningún texto constitucional y por ello la doctrina la veía como ligada lógica y conceptualmente a este texto, puesto que la condena constitucional de la degradación de la persona humana implica necesariamente el reconocimiento de su dignidad. Según Bertrand Mathieu, la degradación de la persona humana reenvía necesariamente y, entre otras, a las experiencias "médicas" y eugenésicas de la Alemania nazi. v. su nota, RFDA, vol. 10, núm. 5, septiembre-octubre 1994, pp. 1021 y ss. 
14. Ahora bien, la deficiente argumentación en materia de vivienda se encuentra para algunos doctrinarios en su débil anclaje textual. ${ }^{17} \mathrm{~A}$ pesar de su consagración en ciertos textos internacionales como la Declaración Universal de los Derechos Humanos, ${ }^{18}$ la "dignidad", en cuanto tal, no es nombrada por ningún texto constitucional francés. Si esta noción se aplica en materia de manipulaciones genéticas, es difícil de transpolar al campo de la vivienda. Esto puede explicar que ningún párrafo del Preámbulo de 1946 fue mencionado en la decisión que consagra el objetivo de valor constitucional de la vivienda digna, sino que el mismo fue citado enteramente, contrario a la decisión "bioética" del 27 de julio de 1994. La crítica es entonces relativa a una interpretación vaga del principio de dignidad. $\mathrm{El}$ riesgo es el de perder la especificidad de la noción "diluida, rebajada al nivel de cualquier derecho social". ${ }^{19}$

15. Otros estiman que sería inoportuno culpar al Consejo Constitucional por este avance jurisprudencial. En primer lugar, esta disposición permite otorgar un contenido cualitativo a la protección del ser humano y de su libertad. El principio de dignidad devendría, junto con el de libertad e igualdad, el tercer gran principio constitucional protector de los derechos humanos en Francia. En efecto, tendría vocación de reagrupar todos los derechos sociales. Como señaló François Luchaire: "La dignidad del ser humano resume esencialmente lo que podemos clasificar como una segunda generación de derechos y libertades... El Preámbulo de 1946 tiene por objeto esencial el de exigir de la sociedad misma no solamente

17 En su nota en LPA, 7 de junio de 1995, pp. 9-10, Bertrand Mathieu juzga esta referencia a la noción de dignidad humana como superabundante.

18 Declaración Universal de los Derechos Humanos, preámbulo.

19 Mathieu, Bertrand, "La dignité de la personne humaine: quel droit? Quel titulaire?" [La dignidad de la persona humana: ¿Qué derecho? ¿Qué titular?], Recueil Dalloz, 1996, 33er. cuaderno, crónica, p. 285. Desde el punto de vista jusfilosófico, el jusnaturalismo racionalista kantiano mostró desde siempre una centralidad en la consideración de la dignidad humana. Así, por ejemplo: "La dignidad que consagra la esencia misma del hombre es considerada como un derecho natural fundamental, preexistente a toda construcción jurídica, y que trasciende a los otros derechos y libertades. Ella testimonia de la exigencia ética suprema pues este derecho tiene carácter absoluto: se trata de un «imperativo categórico» según Kant". Cfr. Godfrin, Valérie, "Le droit au logement: un exemple de l'influence des droits fondamentaux sur le droit de propriété" [El derecho a la vivienda: un ejemplo de la influencia de los derechos fundamentales sobre el derecho de propiedad] en Pédrot, Philippe (dir.), Éthique, droit et dignité de la personne humaine [Ética, derecho y dignidad de la persona humana], París, Economica, 1999, p. 150.

Esta obra está bajo una Licencia Creative Commons

Atribución-NoComercial-SinDerivar 4.0 Internacional, IIJ-UNAM.

Boletín Mexicano de Derecho Comparado, núm. 152, pp. 599-626. 
abstenciones, sino también la prestaciones materialmente indispensables para la dignidad del ser humano". ${ }^{20}$ En segundo lugar, se ha dicho que allí se encuentra justamente el carácter innovador de la decisión. Las malas condiciones habitacionales implican "formas de degradación" y el principio de la dignidad postula asimismo la igualdad de todos los miembros de la comunidad, lo que se opone a prácticas discriminatorias. La necesaria interdependencia de los miembros de la colectividad impone la obligación para cada uno de ellos de respetar y ayudar a sus semejantes. Así, la perspectiva abierta por el juez no es la de un recurso individual accesible a quienes sufren de precariedad habitacional; el derecho a la dignidad es concebido como fuente de una obligación positiva que pesa sobre la totalidad de la colectividad (deber de solidaridad). ${ }^{21}$ Finalmente, otro sector doctrinal señala que podemos concebir el principio de dignidad como un principio "matriz" que permite al juez constitucional operar su control con base en postulados verdaderamente fundamentales. ${ }^{22}$

16. Con todo, la fórmula utilizada por el Consejo Constitucional pareciera atestiguar de una cierta ambigüedad. En efecto, algunos autores muestran que la yuxtaposición de los términos "objetivo" y "posibilidad" corresponde a un mecanismo hábil para vaciar de contenido el contencioso entre los diputados requirentes y las observaciones del gobierno en réplica. ${ }^{23}$

20 Cfr. Jorion, Benoît, AfDA, 20 de junio de 1995, op. cit., nota al pie núm. 11, p. 457.

21 V. Zitouni, François, "Le Conseil Constitutionnel et le logement des plus démunis" [El Consejo Constitucional y la vivienda de los más desposeídos], cit., nota al pie núm. 14, p. 18.

22 "Ciertos principios devienen principios mayores, «principios-matriz», pues engendran otros derechos de alcances y valores diferentes: El derecho a la dignidad es la matriz de un cierto número de garantías que formalmente son legales, pero cuya protección es necesaria para asegurar el respeto del principio en sí mismo. Él sirve igualmente de fundamento a un objetivo constitucional, el de la vivienda digna... Esta política de «principios-matriz» permite al juez constitucional hacer versar su control sobre el respeto de los principios verdaderamente fundamentales ligados a la Constitución y cuya invocación no puede ser objeto de cuestionamiento". Cfr. Mathieu, Bertrand, "Pour une reconnaissance de 'principes matriciels' en matière de protection des droits de l'homme" [Por un reconocimiento de los "principios-matriz" en materia de protección de los derechos humanos], Recueil Dalloz, 1995, 27 o. cuaderno, crónica, pp. A-27 y A-28.

23 Sales, Eric, Le droit au logement dans la jurisprudence française. Etude comparée des jurisprudences constitutionnelle, administrative et judiciaire [El derecho a la vivienda en la jurisprudencia francesa. Estudio comparado de la jurisprudencia constitucional, administrativa y judicial] (tesis), Univ. Montpellier I, 2000, p. 164. 
17. La principal consecuencia del desarrollo de este objetivo de valor constitucional es la consagración de un mecanismo para encuadrar la legislación.

\section{UN MEGANISMO PARA ENGUADRAR LA LEGISLACIÓN}

18. El dispositivo del objetivo de valor constitucional consiste en una articulación entre objetivos planteados a nivel constitucional y medios definidos a nivel legislativo. En derecho francés, la expresión "objetivo de valor constitucional” nació en ocasión de la decisión del Consejo Constitucional número 82-141 DG del 27 de julio de 1982 relativa a la ley sobre la comunicación audiovisual. Esta decisión operó la conciliación efectuada por el legislador entre el ejercicio de la libertad de comunicación resultante del artículo 11 DDDHC y "...los objetivos de valor constitucional que son la salvaguarda del orden público, el respeto de la libertad ajena y la preservación del carácter pluralista de las corrientes de expresión socioculturales". ${ }^{24}$ A través de esta institución, el juez constitucional sujetó a una categoría jurídica vastos sectores de la vida nacional, tales como los objetivos de pacificación social en las relaciones de trabajo y de pluralismo y transparencia financiera de las empresas de prensa. Posteriormente, los objetivos de protección de la salud pública, de salvaguarda del orden público, de continuidad de los servicios públicos, de respeto a la libertad ajena y de lucha contra los fraudes fiscales fueron enunciados hasta la consagración del objetivo de valor constitucional de la posibilidad para toda persona de disponer de una vivienda digna. Se trata, este último, de un objetivo que será nombrado en numerosas ocasiones. ${ }^{25}$

24 Faure, Bertrand, "Les objectifs de valeur constitutionnelle: une nouvelle catégorie juridique?" [Los objetivos de valor constitucional: ¿Una nueva categoría jurídica?], RFDC, 1995, p. 47. El autor muestra que, en realidad, la primera decisión en la materia es la núm. 80-127 DC del 19 y 20 de enero de 1981.

La clasificación de los objetivos de valor constitucional es presentada en tanto desmembramientos del interés general o caracterizados como respuestas constitucionales en los campos económicos y sociales en Verpeaux, Michel y Mathieu, Bertrand, Droit constitutionnel [Derecho constitucional], París, PUF, 2004, p. 263.

25 C. C., decisión núm. 95-371 DC del 29 de diciembre de 1995, Ley de finanzas rectificativa para 1995, recueil, p. 265, cons. núm. 6; decisión núm. 98-403 DG del 29 de julio de 1998, Impuesto sobre inhabilitaciones, recueil, p. 276, cons. núm. 4, 7 y 37; decisión núm. 2000436 DC del 7 de diciembre de 2000, Ley relativa a la solidaridad y renovación urbanas, recueil, p. 176, cons. núm. 50 y 54 ; decisión núm. 2001-455 DC del 12 de enero de 2002, Ley de

Esta obra está bajo una Licencia Creative Commons

Atribución-NoComercial-SinDerivar 4.0 Internacional, IIJ-UNAM.

Boletín Mexicano de Derecho Comparado, núm. 152, pp. 599-626. 
19. La naturaleza de los objetivos de valor constitucional se orienta a encuadrar la legislación. Como se observa, el derecho no es aquí considerado como un "orden de coacción" (Kelsen) sino de manera teleológica (A), para el futuro $(\mathrm{B})$.

\section{Una noción constitucional teleológica}

20. Se trata de un mecanismo que fija las orientaciones y las prioridades a seguir. Los objetivos de valor constitucional no suponen una regla de conducta material sino que imponen un objetivo a perseguir por el legislador y que no implica derechos subjetivos.

21. En derecho francés, el matiz entre derecho, principio y objetivo de valor constitucional es de importancia. Este último permite, en primer lugar, diferenciar las normas de referencia entre ellas, en cuanto a su naturaleza y en cuanto a su alcance. En efecto, el objetivo de valor constitucional no tiene un carácter normativo tal como el de los principios y reglas de valor constitucional sino de una norma de aplicación de un principio o de una regla en un sector o campo determinado. En segundo lugar, el objetivo de valor constitucional permite canalizar u orientar el ejercicio de un derecho o de una libertad fundamental, tornando más fácil la conciliación de normas constitucionales entre sí y su puesta en marcha por el legislador. La mayor originalidad de los objetivos reside en su naturaleza finalista, al costado de las formas jurídicas tradicionales.

22. La ausencia de derecho subjetivo fue desde el principio claramente identificada en Francia cuando los objetivos de valor constitucional fueron analizados. Así: “...son imperativos ligados a la vida en sociedad, cuya consideración se impone al legislador, y que justifican limitaciones a los derechos y libertades clásicos... Los derechos-acreencia no son derechos subjetivos sino objetivos cuya puesta en marcha se impone al Estado y que benefician de un rol correctivo respecto de los principios de esencia liberal. Se trata, esencialmente, de principios directores que deben guiar al legislador" ${ }^{26}$ en su comportamiento futuro.

modernizaciones sociales, 70 del 18 de enero de 2002, p. 1053, cons. núm. 94; decisión núm. 2009-578 DC del 18 de marzo de 2009, Ley de movilización por la vivienda y la lucha contra la exclusión, 70 del 27 de marzo de 2009, p. 5445, cons. núm. 12 y 14.

26 Cfr. Verpeaux, Michel y Mathieu, Bertrand, Droit constitutionnel [Derecho constitucional], cit., nota al pie núm. 24, p. 263. 


\section{Una noción constitucional para el futuro}

23. Si el objetivo de valor constitucional busca encuadrar la legislación futura, podemos preguntarnos en qué medida el derecho francés reconoce un dispositivo de progresividad (1) y si él permite un control de la omisión inconstitucional (2).

\section{A. Una progresividad limitada}

24. La calificación de objetivo de valor constitucional se asociaba doctrinariamente a la jurisprudencia llamada del efecto "anti retorno" y, al mismo tiempo, a la del efecto "piso". Según ciertos autores, la primera de estas categorías fue mencionada por el Consejo Constitucional en su decisión que calificó como objetivo de valor constitucional la posibilidad de disponer de una vivienda digna. Según esta técnica “...lo que se prohíbe es la regresión, no la progresión de un derecho o de una libertad fundamental". ${ }^{27}$ Sin embargo, otra corriente doctrinaria rechazó desde el principio el efecto "anti retorno" en materia de vivienda. En efecto el "constantemente más" siempre fue rechazado en materia social ${ }^{28}$ y debemos considerar que el estado actual de la jurisprudencia lo ha abandonado en su totalidad, puesto que el Consejo Constitucional se niega a instaurar una regla de no retorno hacia atrás. ${ }^{29}$ En materia de vivienda, ciertos autores señalaron que “...el límite marcado al legislador no es una prohibición en general, sino una regresión

27 Cons. núm. 8, decisión núm. 95-359 DC del 19 de enero de 1995 precitada: “...el legislador puede a tales fines modificar, completar o derogar las disposiciones legislativas promulgadas anteriormente con la única condición de no privar de garantías legales los principios constitucionales cuya puesta en vigencia tenían por objeto las mismas". Cfr. Gaïa, Patrick, nota a la decisión núm. 95-359 DC del 19 de enero de 1995, RFDC, 1995, núm. 23, p. 584.

28 "En efecto, es tan simple utilizar la técnica del efecto «anti retorno» para las garantías jurídicas establecidas en materia de libertades, las que otra ley no podría disminuir, como para nada evidente utilizar esta técnica en materia de derechos-prestación frente a los cuales el margen de indeterminación otorgado al legislador es necesariamente más grande". Cfr. nota a la decisión núm. 95-359 DC del 19 de enero de 1995 de Jorion, Benoît, AJDA, 20 de junio de 1995, p. 462.

29 Vidal-Naquet, Ariane, Les garanties légales des exigences constitutionnelles dans la jurisprudence du Conseil Constitutionnel [Las garantías legales de las exigencias constitucionales en la jurisprudencia del Consejo Constitucional], tesis, Univ. Panthéon Assas, París II, 2004, pp. 227 y ss.

Esta obra está bajo una Licencia Creative Commons

Atribución-NoComercial-SinDerivar 4.0 Internacional, IIJ-UNAM.

Boletín Mexicano de Derecho Comparado, núm. 152, pp. 599-626. 
tal que afecte en su esencia el derecho a condiciones de vida digna". ${ }^{30}$ Podríamos creer entonces que el objetivo constitucional de la vivienda digna beneficia de un efecto "piso", según el cual, la reducción del alcance de un derecho es aceptable pero siempre debe existir un piso mínimo impenetrable. Sin embargo, y según una investigación doctoral, la mención a las "garantías legales de las exigencias constitucionales" no implica un efecto "anti retorno" ni un efecto "piso" sino una categoría jurídica específica y autónoma que permite sintetizar estas expresiones jurisprudenciales. Ello significa, por un lado, que el control ejercido por el Consejo Constitucional sobre las modalidades de protección del derecho a la vivienda no depende de la legislación anterior. Al contrario, se ejerce también ante la hipótesis de situaciones nuevas. Por otro lado, nada asegura que la legislación anterior sea constitucionalmente adecuada, ni siquiera respecto de un estándar mínimo. Finalmente, el recurso a la noción de garantías legales de las exigencias constitucionales no reside en la interdicción de una regresión apreciada in abstracto sino en la existencia de un umbral modulable que se aprecia en condiciones concretas. "La movilidad de este umbral permite igualmente reservar en provecho del legislador diversas posibilidades de acción, sea que mejora las garantías de que disponen los ciudadanos... sea que las modifica en un sentido diferente, a partir del momento en que son preservadas las garantías legales de las exigencias constitucionales". ${ }^{31}$

25. Podemos percibir entonces que el alcance de la idea de progresividad jurídica en materia de vivienda es muy limitado. Sin embargo, debemos considerar que una posible sanción de la omisión inconstitucional puede tener lugar.

\section{B. Una posible sanción de la omisión inconstitucional}

26. En teoría constitucional general, es decir, fuera del análisis de un Estado de derecho determinado, la inconstitucionalidad por omisión es el incumplimiento total o parcial de los mandatos concretos contenidos en las normas constitucionales por inacción de los poderes constituidos durante

\footnotetext{
30 Cfr. Mathieu, Bertrand, A. I. F. C., 1997, XIII, p. 440.

$31 C f r$. Vidal-Naquet, Ariane, Les garanties légales des exigences constitutionnelles dans la jurisprudence du Conseil Constitutionnel [Las garantías legales de las exigencias constitucionales en la jurisprudencia del Consejo Constitucional], tesis, cit., nota al pie núm. 29, p. 239.
} 
un plazo establecido en la Constitución o considerado razonable por otros medios. Este dispositivo se explica, sea por una fuerza normativa plena de la supremacía constitucional, sea por una suerte de "derecho a la norma". Concretamente, el control de la inconstitucionalidad por omisión evita que tal o cual disposición constitucional sea platónica por la sola inacción de los poderes constituidos, típicamente de la legislatura.

27. En el derecho constitucional extranjero, la Constitución de la ex Yugoslavia del 27 de febrero de 1974 consagró por primera vez el instituto de la omisión inconstitucional. ${ }^{32}$ Entre los textos en vigor, el artículo 283 de la Constitución portuguesa declara: "Cuando el Tribunal verifique la existencia de una inconstitucionalidad por omisión dará conocimiento de ello al órgano legislativo competente". En América Latina, el artículo 103, inciso 2, de la Constitución brasileña y la Constitución de Venezuela $^{33}$ señalan un procedimiento en caso de omisión inconstitucional. Por vía jurisprudencial, la inconstitucionalidad por omisión se desarrolló en países como Austria, Estados Unidos, España y, recientemente, Colombia. ${ }^{34}$ Entre los países que consagraron este mecanismo a partir de normas infra constitucionales encontramos a Costa Rica, a través la Ley número 7135 de jurisdicción constitucional ${ }^{35}$ y a República Dominicana, a través el artículo 29, inciso 2, de la Ley número 821 de organización jurisdiccional.

28. Según la reflexión doctrinal francesa, el objetivo de valor constitucional se asemeja en ocasiones a un control de la omisión inconstitucional. ${ }^{36}$ El mismo significa una evolución en la producción jurídica del Estado, dando lugar así a una legalidad programática. La competencia finalista del objetivo del legislador no se acompaña, sin embargo, de un método de interpretación teleológico según el cual el juez deduciría del objetivo todo poder útil a su realización. Por el contrario, la ley es examinada más bien a la luz de la contribución que aporta a la concreción del

\footnotetext{
32 Artículo 377.

33 Artículo 336.

34 Véase por todos Bazan, Víctor, "La inconstitucionalidad por omisión en el derecho comparado", Anuario de Derecho Constitucional Latinoamericano, México, UNAM, 2006, p. 502.

35 Artículo 29.

36 Godfrin, Valérie, "Le droit au logement: un exemple de l'influence des droits fondamentaux sur le droit de propriété" [El derecho a la vivienda: un ejemplo de la influencia de los derechos fundamentales sobre el derecho de propiedad], cit., nota al pie núm. 19, p. 154.
}

Esta obra está bajo una Licencia Creative Commons

Atribución-NoComercial-SinDerivar 4.0 Internacional, IIJ-UNAM.

Boletín Mexicano de Derecho Comparado, núm. 152, pp. 599-626. 
objetivo. En efecto, la inconstitucionalidad de una ley puede surgir, por una parte, de una violación pura y simple de un objetivo de valor constitucional. Este caso supone un control tradicional de la no conformidad de una ley al objetivo, en la especie, la posibilidad de disponer de una vivienda digna. Se trata del irrespeto de la Constitución en su carácter de norma superior. En este punto, los objetivos de valor constitucional serían asimilables a otras reglas y principios constitucionales. Pero, por otra parte, una ley puede ser censurada en razón de la no realización de un objetivo constitucional. El control cambia en este caso de método y el examen versa aquí sobre la relación entre el objetivo buscado y los medios definidos por el legislador: Se comparan los resultados obtenidos con los resultados deseados. Esta técnica, que podríamos considerar de evaluación legislativa, provoca la salida del juez de la estricta constatación del respeto de la jerarquía normativa. Si “...la utilidad de la ley deviene así la condición de la su constitucionalidad", ${ }^{37}$ el derecho francés ha tomado uno de los aspectos del control de las omisiones inconstitucionales: el de sancionar la inconstitucionalidad de las leyes que no satisfacen suficientemente el objetivo buscado. Así, el juez constitucional verificó en numerosas ocasiones el grado de realización del objetivo. En su decisión número 98-403 DC del 29 de julio de 1998 sobre la ley relativa a la diversidad del hábitat, ${ }^{38}$ él consideró que el legislador no había desconocido ninguna de las garantías legales asociadas a la puesta en marcha de los principios constitucionales de desarrollo de la persona y de la familia, de seguridad material y, sobre todo, de dignidad que fundan el objetivo de la posibilidad de disponer de una vivienda digna. ${ }^{39}$ En su decisión número 98-403 DC del 29 de julio de 1998, el Consejo Constitucional examinó la conformidad a la Constitución de la ley de orientación relativa a la lucha contra las exclusiones. ${ }^{40}$ El objeto de la imposición tributaria establecida era el de incitar a los

37 Faure, Bertrand, "Les objectifs de valeur constitutionnelle: Une nouvelle catégorie juridique?” [Los objetivos de valor constitucional: ¿Una nueva categoría jurídica?], cit., nota al pie núm. 24, p. 69.

38 Ley núm. 94-624 del 21 de julio de 1994.

39 "L'examen par le Conseil constitutionnel de la loi d'orientation relative à la lutte contre les exclusions" [El examen del Consejo Constitucional de la Ley de Orientación Relativa a la Lucha Contra las Exclusiones], LPA, 31 de julio de 1998, núm. 91, pp. 3 y 4 [sin firma].

40 Ley núm. 98-657 del 29 de julio de 1998.

Esta obra está bajo una Licencia Creative Commons Atribución-NoComercial-SinDerivar 4.0 Internacional, IIJ-UNAM. Boletín Mexicano de Derecho Comparado, núm. 152, pp. 599-626. 
propietarios concernidos a poner en alquiler las viviendas vacantes susceptibles de ser arrendadas. Según el Consejo, ésta tenía por finalidad responder al objetivo de valor constitucional del acceso a una vivienda digna, aumentando la oferta de viviendas destinadas a personas desfavorecidas. ${ }^{41}$ Finalmente, el Consejo Constitucional declaró en $2009^{42}$ que era posible que el legislador modificara, incluso para los acuerdos en curso, el marco legal aplicable a la atribución de viviendas y a la resciliación de tales contratos pues "...estas disposiciones contribuyen a la puesta en marcha del objetivo de valor constitucional que constituye la posibilidad para toda persona de disponer de una vivienda digna". ${ }^{43}$

29. Desde la perspectiva de la eficacia normativa de la Constitución, resulta paradójico verificar que el derecho constitucional de un Estado que no consagra expresamente un derecho a la vivienda haya desarrollado una suerte de control de la omisión inconstitucional por la vía jurisprudencial. Profundizaremos entonces a continuación las principales consecuencias contenciosas de este objetivo de valor constitucional.

\section{EL OBJETIVO DE VALOR GONSTITUCIONAL DE LA VIVIENDA DIGNA EN EL CONTENCIOSO CONSTITUCIONAL}

30. El derecho francés no dispone de un mecanismo comparable al amparo del derecho latinoamericano o español. Sin embargo, este instituto guarda ciertas similitudes con el référé que constituye una vía procesal idónea para salvaguardar derechos fundamentales en el marco de un contencioso de una particular rapidez. A nuestros fines, nos referiremos al référé administratif.

31. En 2002, el Consejo de Estado había pronunciado un fallo Epoux Fofana, rechazando considerar el "derecho a la vivienda" invocado por el requirente bajo forma de una libertad fundamental, en el marco de un référé-liberté. El Consejo declaró en ese momento: “...las circunstancias del caso no demuestran ninguna afección grave y manifiestamente ilegal a una libertad fundamental por una persona jurídica de derecho público

41 Guiselin, Emmanuel-Pie, "L'accès à un logement décent et le droit de propriété: Ni vainqueur ni vaincu" [El acceso a una vivienda digna y el derecho de propiedad: ni vencedor ni vencido], LPA, 13 de marzo de 2000, núm. 51, p. 10.

42 Decisión núm. 2009-578 DG precitada.

43 Decisión núm. 2009-578 DC precitada, cons. núm. 14 in fine.

Esta obra está bajo una Licencia Creative Commons

Atribución-NoComercial-SinDerivar 4.0 Internacional, IIJ-UNAM.

Boletín Mexicano de Derecho Comparado, núm. 152, pp. 599-626. 
en ejercicio de sus funciones". ${ }^{44} \mathrm{El}$ "derecho a la vivienda" no constituía una libertad fundamental susceptible de permitir la puesta en marcha del référé-liberté en los términos del ley del 30 de junio de $2000 .{ }^{45}$ La ley del 5 de marzo de $2007,{ }^{46}$ por su parte, ha concretado este derecho a nivel legal gracias al mecanismo del derecho "oponible". Fue con base en el procedimiento instituido por esta ley ${ }^{47}$ que el Tribunal Administrativo de París ${ }^{48}$ intervino en la causa Fofana II en un procedimiento de référé-suspension. ${ }^{49}$ Alojada precariamente con dos hijos, desde junio de 2006 en el Centro de Albergue y Reinserción Social (CHRS), la requirente peticionó el 4 de enero de 2008 a la Comisión de Mediación de París que ésta declarara el carácter urgente y prioritario de la atribución de una vivienda. Sin embargo, reunida el 28 de febrero de 2008, la Comisión había pronunciado un dictamen desfavorable motivado en la obligación de la peticionante de presentar previamente su permiso de residencia en Francia. Ahora bien, dado que esta exigencia no estaba prevista por la ley, la requirente demandó ante el Tribunal Administrativo de París, por la vía de un recurso en anulación completado por un référé-suspension, contra el dictamen. El cuadro normativo se encuentra en que el legislador ha previsto que el dictamen de la Comisión no puede ser recurrido sino cuando, en un plazo de 6 meses, ninguna propuesta de vivienda fuere efectuada teniendo en cuenta las necesidades y las capacidades del peticionante. Ello indicaba que la decisión de la Comisión era susceptible de una demanda de anulación y de una de suspensión, pues existía duda seria sobre su legalidad.

32. Desde su consagración, el objetivo de valor constitucional para toda persona de disponer de una vivienda digna atrajo la atención a propósito de las tensiones que puede engendrar con el derecho de propiedad, en razón de su antinomia irreductible (A). A tal punto ello fue así que,

\footnotetext{
44 C. E., référé del 22 de mayo de 2002, núm. 242193.

45 Código de Justicia Administrativa, artículo L521-2. En sentido de excluir el référé-liberté en materia de vivienda véase C. E., référé del 3 de mayo de 2002, núm. 245687, "Association de réinsertion sociale du Limousin".

46 Ley núm. 2007-290 instituyendo un derecho oponible a la vivienda y versando sobre diversas medidas a favor de la cohesión social.

47 T. A. París, référé del 20 de mayo de 2008, "Mme. Fofana et Association Droit au logement Paris et ses environs", núm. 0807829/9/1.

48 Código de Justicia Administrativa, artículo L. 441-2-3.

49 Ibidem, artículo L.521-1.
} 
incluso antes de que el Consejo Constitucional se pronunciara sobre el conflicto entre ambos, una parte de la doctrina predecía que "...en razón de tal objetivo, podemos asistir a una desaparición total del carácter fundamental del derecho de propiedad" ${ }^{50}$ Por otra parte, el objetivo de valor constitucional de la vivienda digna puede dar lugar a restricciones a otros derechos y libertades constitucionales (B).

\section{Las restricciones al derecho de propiedad}

33. El Consejo Constitucional calificó el derecho de propiedad como un derecho fundamental dotado de "pleno valor constitucional" que constituye "uno de los objetivos de la sociedad política". ${ }^{51}$ El derecho de propiedad así inscripto en el texto constitucional no tolera restricciones de parte del legislador que tiendan a desnaturalizarlo sino únicamente en nombre del interés general. ${ }^{52}$ Los fundamentos normativos de tal carácter fundamental son el artículo 2o. de la DDHC de 1789 que ubica este derecho como de rango natural y el artículo 17 de la misma Declaración que le otorga carácter inviolable y sagrado.

34. En su decisión número 98-403 DC del 29 de julio de 1998, el juez constitucional examinó la conformidad a la Constitución de la ley de orientación relativa a la lucha contra las exclusiones. ${ }^{53}$ El Alto Consejo no

50 Cfr. Pauliat, Hélène, "L'objectif constitutionnel du droit au logement décent : Vers le constat du décès du droit de propriété?" [El objetivo constitucional del derecho a la vivienda digna: ¿Hacia la constatación de fallecimiento del derecho de propiedad?], Recueil Dalloz, 37o. cuaderno, 1995, p. A-37. La predicción de esta autora es que el derecho de propiedad podría desaparecer en tanto derecho fundamental en beneficio de un reconocimiento y consagración de sus desmembramientos caso por caso. Ella se funda, primeramente, en la ausencia de jerarquía entre las normas constitucionales. Seguidamente, en las limitaciones ya conocidas al derecho de propiedad. Por último, sostiene que los desmembramientos del derecho de propiedad, en particular el abusus, se verían gravemente afectados. Su análisis global versa sobre las múltiples restricciones al derecho de propiedad toleradas por el juez constitucional.

51 Decisión núm. 82-132 DC del 16 de enero de 1982, "Ley de nacionalización”, recueil p. 18.

52 La decisión núm. 89-256 DC del 25 de julio de 1989 acepta una extensión del derecho de propiedad adaptada a las nuevas intervenciones públicas en los términos de la decisión núm. 89-256 DC del 20 de julio de 1983: "limitaciones exigidas por el interés general".

53 Ley núm. 98-657 del 29 de julio de 1998.

Esta obra está bajo una Licencia Creative Commons

Atribución-NoComercial-SinDerivar 4.0 Internacional, IIJ-UNAM.

Boletín Mexicano de Derecho Comparado, núm. 152, pp. 599-626. 
declaró la inconstitucionalidad de la instauración de una obligación tributaria anual sobre las viviendas vacantes en las comunas pertenecientes a ciertas zonas de urbanización de más de 200,000 habitantes en caso de que exista un desequilibrio entre la oferta y la demanda. El objeto de tal tributación era el de incitar a los propietarios concernidos a alquilar sus viviendas vacantes. El Consejo admitió también un nuevo procedimiento de inspección de inmuebles destinados a la vivienda, el cual, según consideró, no constituye una privación del derecho de propiedad en el sentido del artículo 17 de la Declaración de 1789. Por el contrario, ella tiende a responder al objetivo de valor constitucional de la posibilidad de disponer de una morada digna, aumentando la oferta de viviendas destinadas a las personas desfavorecidas. No obstante, se declaró la inconstitucionalidad de cuatro artículos, de los cuales dos habían sido cuestionados por los requirentes y los otros dos fueron invocados ex officio. El dispositivo del artículo 107 de la ley podía, efectivamente, conducir a que el acreedor sea declarado arrendador de oficio de un bien a un precio cuya determinación no necesitaba de su acuerdo. Asimismo, en ciertos casos, la ley permitía una disminución de su patrimonio sin calificación de necesidad pública y sin indemnización. Este artículo 107 desconocía, para el Consejo, el derecho de disponer libremente del patrimonio, siendo el mismo un atributo esencial del derecho de propiedad. Los artículos 109 y 110, inseparables del artículo 107, fueron declarados inconstitucionales por vía de consecuencia. Seguidamente, en ocasión de la decisión número 2000-436 del 7 de diciembre de 2000, relativa a la Ley de Solidaridad y Renovación Urbana, el Consejo se pronunció nuevamente sobre la limitación al derecho de propiedad precisando que "...los requirentes atacan el alcance de las disposiciones cuestionadas, las que ponen en marcha un procedimiento consultivo". ${ }^{44}$ Así, no hay afectación de "...ninguno de los atributos del derecho de propiedad", ${ }^{55}$ dado que el Consejo de Concertación de Alquileres es consultado sobre los proyectos en relación a la gestión del inmueble. No poseen, entonces, ninguna competencia comparable a la del propietario en materia de afectación de su patrimonio.

54 Véase nota de Schoëttl, Jean-Eric, AfDA, 20 de enero de 2001, p. 18.

55 Cfr. Sales, Eric, Le droit au logement dans la jurisprudence française. Etude comparée des jurisprudences constitutionnelle, administrative et judiciaire [El derecho a la vivienda en la jurisprudencia francesa. Estudio comparado de la jurisprudencia constitucional, administrativa y judicial] (tesis), cit., nota al pie núm. 23, p. 242.

Esta obra está bajo una Licencia Creative Commons Atribución-NoComercial-SinDerivar 4.0 Internacional, IIJ-UNAM. Boletín Mexicano de Derecho Comparado, núm. 152, pp. 599-626. 
35. Ahora bien, ¿hay una verdadera afectación del carácter fundamental del derecho de propiedad en nombre del objetivo de valor constitucional de la vivienda digna? La respuesta no puede ser sino negativa. Por un lado, el derecho propiedad únicamente se ve afectado en el abusus (1). Por otro lado, el mismo se encuentra aún protegido (2).

\section{A. Un derecho de propiedad únicamente afectado en el abusus}

36. En derecho francés, resulta totalmente concebible considerar que no resulta afectado el derecho de propiedad en su totalidad sino una de sus desmembraciones. Ello así por cuanto

...el derecho de propiedad tal y como es reconocido por el Consejo Constitucional no tiene exactamente las mismas características que el derecho clásico reconocido en el artículo 544 del Código Civil... El derecho de propiedad se descompone normalmente en usus, fructus y abusus. El abusus significa que se puede disponer completamente de la cosa, incluso consumirla completamente, hacerla desaparecer o abandonarla. De la lectura de los precedentes, pareciera que es este prisma el que resultaría particularmente amenazado por el objetivo de valor constitucional de la vivienda digna. El abusus no existiría sino dentro de ciertos límites bastante rígidos: si el propietario no desea que su inmueble sea solicitado para una vivienda social, él dispone de la posibilidad de habitarlo o de venderlo. La libertad de elección es entonces relativa... El objetivo constitucional puede forzar a un propietario a aceptar los pedidos de albergar personas, sin que pueda oponerse en función del derecho de propiedad. ${ }^{56}$

De esta manera, la posibilidad de obtener una vivienda digna se sitúa lejos de cuestionar el valor fundamental del derecho de propiedad. Sería así en caso de desposesión sin indemnización previa, hipótesis que no se verifica en la jurisprudencia. De la misma manera, en caso de limitaciones no constitutivas de una desposesión pero presentando un carácter tal que el sentido y el alcance del derecho de propiedad se encontrasen desnaturalizados. Por el contrario, el Consejo Constitucional se asegura de que el

56 Pauliat, Hélène, "L’objectif constitutionnel du droit au logement décent: Vers le constat du décès du droit de propriété?" [El objetivo constitucional del derecho a la vivienda digna: ¿Hacia la constatación de fallecimiento del derecho de propiedad?], cit., nota al pie núm. 50, p. 286.

Esta obra está bajo una Licencia Creative Commons

Atribución-NoComercial-SinDerivar 4.0 Internacional, IIJ-UNAM.

Boletín Mexicano de Derecho Comparado, núm. 152, pp. 599-626. 
derecho de propiedad no sea desnaturalizado cuando el legislador amplía las posibilidades de imposición de puesta a disposición de la vivienda o cuando modifica las condiciones de venta en subasta de la vivienda de un deudor moroso. Por otra parte, la lógica interna de los principios y reglas de valor constitucional debe ser recordada: la posibilidad de obtener una vivienda digna no se sitúa en el mismo plano que el derecho de propiedad. Este último constituye un derecho constitucional, mientras que aquélla no representa sino un objetivo de valor constitucional. ${ }^{57}$ Simplemente, el derecho de propiedad fue objeto de un nuevo matiz que se puede insertar en el pasaje de una concepción completamente individualista a una de la propiedad en función social.

37. En efecto, la propiedad se tradujo en el Código Civil a manera de pleonasmo. Este derecho se presentaba para su titular como la emergencia de lo particular sobre lo colectivo, se trataba del derecho de un hombre contra todos los otros. Sin embargo, desde finales del siglo XIX y principios del XX, el derecho de propiedad se vio confrontado a la eclosión de las doctrinas sociales que marcaron una ruptura con la concepción puramente individualista y absolutista de este derecho. La tesis de León Duguit relativa a la función social de la propiedad constituye un ejemplo. Ésta desarrolla la idea según la cual el propietario debe, ante todo, emplear la cosa para satisfacción de otros miembros del grupo, para quienes la existencia de ese bien es indispensable. La propiedad es, para Duguit, una institución jurídica concebida para responder a las necesidades económicas y que evoluciona necesariamente con éstas. De esta manera, en 1915, la Corte de Casación sancionó, por vía del ejercicio abusivo de un derecho, la utilización del derecho de propiedad con intención de dañar. ${ }^{58}$ La propiedad, analizada como la libertad en materia de bienes, se encuentra así sujeta al régimen de responsabilidad civil y su abuso puede ser san-

57 Nota de Trémeau, Jérôme, RFDC, 1998, pp. 767 y 768: "Resulta que estas limitaciones deben ellas mismas ser limitadas bajo pena de desnaturalizar el derecho de propiedad. El hecho de que la posibilidad de obtener una vivienda digna sea un objetivo de valor constitucional reviste aquí una gran importancia. En efecto, si se hubiese tratado de un derecho constitucional, el Consejo Constitucional habría controlado la conciliación operada entre dos derechos fundamentales, a saber el derecho de propiedad y el derecho a una vivienda digna. Por el contrario, estando en presencia de un simple fundamento constitucional dirigido al legislador, el juez constitucional se asegura que el ejercicio del mismo no restrinja de manera demasiado importante el derecho de propiedad".

58 Corte de Casación, sentencia del 13 de agosto de 1915, núm. 0002378. 
cionado. La protección constitucional de este derecho fue objeto de este cambio de orientación. El juez constitucional tuvo oportunidad de constatar que desde 1789 “...las finalidades y las condiciones de este derecho fueron objeto de una evolución caracterizada por las limitaciones exigidas por el interés general". ${ }^{59}$ Ello impide, finalmente, otorgarle sin limitaciones un carácter inviolable y sagrado. El reconocimiento del objetivo de valor constitucional de la posibilidad de disponer de una vivienda digna muestra, a partir de este momento, a un juez constitucional que concibe el derecho de propiedad en función social. Así, los diferentes atributos del derecho de propiedad abren la vía a la influencia del interés social. Mientras que la ausencia de usus podía ser absoluta sin implicar sanción alguna, en virtud de la regla según la cual la propiedad no se extingue por su inutilización, aquélla puede en la hora actual ser sancionada por la imposición de puesta a disposición de inmuebles inutilizados. El derecho de propiedad se encuentra empero plenamente protegido.

\section{B. Un derecho de propiedad aún protegido}

38. Ello significa que el legislador no puede fundar en una regla o principio de valor constitucional antagónico una restricción desproporcionada al derecho de propiedad. Para saber si el objetivo de valor constitucional de la vivienda digna tiene algo de particular con respecto a este derecho es necesario analizar el control de proporcionalidad que se opera en materia de otras restricciones al derecho de propiedad.

39. En primer lugar, en la decisión número 90-283 DC del 8 de enero de 1991, Lucha contra el tabaquismo y el alcoholismo, el Consejo Constitucional muestra que la verificación de la ausencia de violación del artículo 17 de la DDHC o de la ausencia de desnaturalización del derecho de propiedad forman parte del mecanismo jurídico del control de proporcionalidad: cuando los requirentes invocan la desnaturalización del derecho de propiedad, el Consejo puede constatar la inexistencia de una transferencia de la misma que entraría en el campo de las previsiones del artículo 17. En su decisión número 84-172 DG del 26 de julio de 1984, Estructura de las explotaciones agrícolas, el juez considera que la extensión

59 Decisión núm. 81-132 DC del 16 de enero de 1982, "Ley de nacionalización”, recueil, p. 18.

Esta obra está bajo una Licencia Creative Commons

Atribución-NoComercial-SinDerivar 4.0 Internacional, IIJ-UNAM.

Boletín Mexicano de Derecho Comparado, núm. 152, pp. 599-626. 
de la aplicación de un régimen de autorización previa para el control de las estructuras de explotación agrícola no posee un carácter de gravedad tal que la afección del derecho de propiedad desnaturalice su sentido y alcance. De la misma manera, en su decisión número 89-254 DC del 4 de julio de 1989, Modalidades de aplicación de las privatizaciones, se declara que la previsión de la posibilidad que detenta el ministro de Economía y Finanzas de oponerse al aumento de participación de una o varias personas en una sociedad privatizada no tiene por efecto desnaturalizar el sentido y alcance del derecho de propiedad. Finalmente, en su decisión número 90-287 DC del 16 de enero de 1991, Salud pública y seguro social, la homologación de tarifas de los establecimientos hospitalarios privados con fines de lucro implican restricciones a las condiciones de ejercicio del derecho de propiedad, pero las mismas no tienen por efecto la desnaturalización de este derecho.

40. Así, según todas estas consideraciones jurisprudenciales previas a la consagración del objetivo de valor constitucional de la vivienda digna, ciertas restricciones al derecho de propiedad no fueron declaradas inconstitucionales.

41. En lo que concierne, por otra parte, las disposiciones legislativas censuradas por el Consejo Constitucional, en razón de restricciones desproporcionadas al derecho de propiedad, se encuentra, en primer lugar, la decisión número 94-346 DG del 21 de julio de 1994, Derechos reales sobre el dominio público. El Consejo se pronunció aquí sobre la inconstitucionalidad en razón de verificar una desnaturalización de la protección del derecho de propiedad pública. En particular, esta ley permitía al beneficiario de una autorización de ocupación del dominio público del Estado disponer de un derecho real sobre las obras realizadas sin que un plazo preciso y definitivo fuera establecido. La ausencia de definición de la duración de los derechos reales tenía por efecto vaciar de contenido el derecho de propiedad. En segundo lugar, en la decisión número 96-373 DC del 9 de abril de 1996, Estatus de la Polinesia, la alta jurisdicción constitucional censuró las disposiciones de la ley orgánica que preveía la autorización obligatoria, bajo pena de nulidad, de toda operación que tuviese por objeto la transferencia entre vivos de una propiedad inmobiliaria, salvo si el comprador fuese de nacionalidad francesa y domiciliado en la Polinesia. De esta manera, la ley fue considerada para organizar un régimen de autorización previo sin precisar los motivos de interés general sobre los 
cuales la administración local debía fundar su decisión. Con respecto a las desmembraciones del derecho de propiedad, en particular a propósito del abusus del que ya hemos hablado, ${ }^{60}$ en las decisiones número 84-172 DC del 26 de julio de 1984, Estructura de las explotaciones agrícolas y número 85-189 DG del 17 de julio de 1985, Principios de planificación, el alto Consejo ya había verificado que el abusus no se viera exageradamente disminuido.

42. En definitiva, si confrontamos las decisiones conciliando el objetivo constitucional de la vivienda digna ${ }^{61}$ a esta jurisprudencia, no visualizamos por qué este objetivo tendría algo de particular. Por el contrario, él se inserta claramente en el marco de otras limitaciones al derecho de propiedad. El Consejo siempre ha controlado que la restricción en cuestión no acabe por "vaciar de contenido el derecho de propiedad" 62 y no es sino ésta la consideración que encontramos en materia de vivienda. En efecto, en ocasión de la decisión número 2000-436 DG del 7 de diciembre de 2000, el juez constitucional declaró la inconstitucionalidad de la disposición legislativa que sujetaba sistemáticamente a la autorización administrativa todo cambio de destino de un local comercial o artesanal. Según sostiene: “...teniendo en cuenta las condiciones de su realización - voluntad de vender del propietario-, la autorización no constituye una expropiación sino una restricción al derecho de propiedad que se ve afectado en uno de sus componentes (abusus)". ${ }^{63}$

43. En consecuencia, la respuesta a la cuestión de saber si hubo algo de verdaderamente novedoso en lo que concierne al derecho de propiedad en razón de la introducción de este objetivo de valor constitucional es, a nuestro entender, negativa. Por un lado, una desnaturalización del derecho de propiedad en función del objetivo de la vivienda digna sería declarada inconstitucional. Por otro lado, estas limitaciones se enmarcan

60 Supra, § III.A.1.

61 Decisiones núm. 98-403 DC del 29 de julio de 1998 y núm. 2000-436 del 7 de diciembre de 2000 precitadas.

62 Decisión núm. 85-198 DC del 13 de diciembre de 1985, "Enmienda Torre Eiffel", RJC I-242.

63 Nota de Shchoettl, Jean-Eric, AfJDA, 20 de enero de 2001, p. 21; Boumedine, Malik, La place de la loi et des contrats dans la garantie du droit à la protection sociale de 1945 à nos jours [E] lugar de la ley y de los contratos en la garantía del derecho a la protección social desde 1945 hasta nuestros días], París, Publibook, 2003, p. 143.

Esta obra está bajo una Licencia Creative Commons

Atribución-NoComercial-SinDerivar 4.0 Internacional, IIJ-UNAM.

Boletín Mexicano de Derecho Comparado, núm. 152, pp. 599-626. 
en el dispositivo de la proporcionalidad de las restricciones a los derechos y libertades constitucionales.

44. En este estadio se plantea el mismo interrogante con respecto a otros derechos y libertades constitucionales.

\section{Las restricciones a otros derechos y libertades constitucionales}

45. En primer lugar, respecto de la libertad contractual, la decisión Solidaridad y renovación urbana del 7 de diciembre de 2000 se pronunció abiertamente a propósito de las modalidades de salvaguarda de la libertad, inscripta en el artículo 4o. de la DDHC, frente a una ley que había congelado la afectación social de ciertos inmuebles pertenecientes, o que habían pertenecido, a la Caja de Depósitos y Consignaciones. La ley modificaba los contratos legalmente concluidos y aquéllos en curso en materia de depósitos y consignaciones y sus asociados, restricción juzgada como grave a la economía de los contratos por el Consejo Constitucional. En la misma decisión, el Consejo se pronuncia con respecto al principio de la libre administración de las colectividades territoriales, cuyo respeto se impone al legislador quien "...puede, con fundamento en los artículos 34 y 72 de la Constitución, sujetar las colectividades territoriales y sus agrupamientos a ciertas obligaciones y cargas" pero

...a condición de que las mismas respondan a ciertas exigencias constitucionales o concurran a ciertos fines de interés general y que ellas no desconozcan las competencias propias de las colectividades concernidas. A su vez, tales restricciones no deben obstaculizar la libre administración de la colectividades concernidas y ellas deben estar definidas de manera precisa en cuanto a su objeto y alcance. ${ }^{64}$

El Consejo no encuentra desconocimiento de la Constitución cuando la ley no impone obligaciones de resultado a las colectividades, pues el objetivo definido en la ley fue formulado de manera imprecisa. ${ }^{65}$ Con

64 Decisión núm. 2000-436 DC del 7 de diciembre de 2000.

65 El contenido de las obligaciones residía en la formulación de los diferentes objetivos enumerados en el artículo 121-1 del Código de Urbanismo: "cohesión social", "desarrollo sustentable", "satisfacción sin discriminaciones de las necesidades presentes y futuras en materia de hábitat, de actividades económicas, deportivas y de interés general", "utilización 
respecto a la fuerza ejecutoria de las decisiones de justicia y su corolario, la separación de poderes, el Consejo se pronunció en su decisión número 98-403 DG precitada. ${ }^{66} \mathrm{El}$ artículo 119 de la ley cuestionada fue declarado contrario a la Constitución en lo que respecta a la obligación del prefecto de asegurar, previamente a la ejecución forzada de un desalojo, que una vivienda fuese propuesta a las personas expulsadas. Dada esta subordinación del recurso a la fuerza pública a una formalidad administrativa previa, el texto desconoció el principio de fuerza ejecutoria y el de separación de poderes. ${ }^{67}$ Por otra parte, en la decisión número 95-371 DC del 29 de diciembre de 1995, en materia de una quita del Estado sobre la Caja de Depósitos y Consignaciones a título de un excedente de subvenciones giradas por el Estado a la Caja Garante de la Vivienda Social,

...el Consejo considera que esta operación, que pertenece al campo de competencias de las leyes de finanzas, es indisociable de otra disposición de la ley que prevé una sustitución de la Caja Garante de la Vivienda Social por de la Caja de Depósitos para ciertas operaciones de crédito. Esta última disposición puede entonces figurar en la ley de finanzas. ${ }^{68}$

El Consejo hace mención al objetivo de valor constitucional de la vivienda digna sin pronunciarse expresamente sobre su restricción. Se deja entrever que el financiamiento de la vivienda social está directamente entrelazado con el objetivo de valor constitucional de la vivienda digna. Finalmente, la decisión número 2001-455 DG del 12 de enero de 2001, Ley de modernizaciones sociales, pertenece igualmente el derecho de los contratos. ${ }^{69}$ En la especie, el artículo 159 de la ley deferida preveía

económica y equilibrada de los espacios naturales", "preservación de la calidad del aire" y "prevención de riesgos tecnológicos, de contaminación y sonoros de toda naturaleza".

66 Nota de Magnin, François, LPA, 28 de septiembre de 1998, núm. 116, p. 4.

67 Cfr. decisión núm. 80-119 DC del 22 de julio de 1980, recueil, p. 46.

68 Cfr. Nota de Verpeaux, Michel y Mathieu, Bertrand, LPA, 13 de marzo de 1996, núm. 32, p. 11.

69 "Disponiendo que el precio de locación de los muebles será fijado «teniendo en cuenta los precios de los muebles y la duración de su amortización», la disposición criticada se inscribe en el marco de la puesta en marcha del objetivo de valor constitucional que constituye la posibilidad para toda persona de disponer de una vivienda digna; que, sin embargo, si el principio de igualdad no prohíbe al legislador imponer a ciertas categorías de personas algunas cargas particulares con vistas a mejorar las condiciones de vida de otras categorías de personas, él no debe desconocer la exigencia del artículo 13 de la

Esta obra está bajo una Licencia Creative Commons

Atribución-NoComercial-SinDerivar 4.0 Internacional, IIJ-UNAM.

Boletín Mexicano de Derecho Comparado, núm. 152, pp. 599-626. 
que cuando los inmuebles destinados a albergar personas en dificultades fueran objeto de locación o sublocación amueblada, el precio del alquiler de los muebles sería fijado por resolución ministerial. El Consejo se pronunció indicando primeramente que estas disposiciones tendían a la puesta en práctica del objetivo de valor constitucional de la vivienda digna. Seguidamente, en cuanto al principio de igualdad, el juez constitucional recuerda que el mismo permite al legislador imponer a algunas categorías de personas ciertas cargas particulares, pero siempre respetando la exigencia del ar-tículo 13 de la Declaración de 1789 y por motivos de interés general. En orden a la libertad contractual, él distingue entre los contratos a concluir y los contratos en curso de ejecución. La resolución ministerial no podría así afectar los contratos legalmente concluidos de manera que desconociera el artículo 4o. de la DDHC. Globalmente, la regla no es contraria a la Constitución siendo que la resolución ministerial no podría en el futuro fijar un precio de locación que afecte la igualdad ante las cargas públicas ni los contratos concluidos.

46. Efectuadas todas estas consideraciones, juzgamos necesario exponer nuestras conclusiones.

\section{CONCLusiones}

47. Una primera conclusión que podemos extraer de nuestro análisis es que el juez constitucional francés se muestra comprometido con la problemática de la vivienda. Testimonio claro de esta preocupación es la ausencia de un acercamiento puramente exégeta al texto constitucional que hubiera impedido la consagración de este objetivo de valor constitucional.

48. Una segunda conclusión es relativa a la textura abierta de los principios del Preámbulo de 1946 y del principio de dignidad de la persona. El pretor se sirve de estas nociones y las moviliza en beneficio del reconocimiento del objetivo constitucional de la vivienda digna.

Declaración de 1789, que, por otra parte, si bien es posible que el legislador modifique por razones de interés general los contratos en curso de ejecución, el mismo no podría afectar la economía de los contratos legalmente concluidos de manera tal de desconocer manifiestamente la libertad que emana del artículo 4 de la Declaración de los Derechos del Hombre y el Ciudadano... Estas exigencias son satisfechas en la especie, bajo reserva de que la resolución ministerial no fije un precio de locación de muebles a un nivel que implique una ruptura de la igualdad ante las cargas públicas". Cffr. cons. núm. 94 y 95. 
49. En tercer término, quizás pueda endilgarse al régimen jurídico que acabamos de exponer la falta de un dispositivo de progresividad en la materia. No obstante, el margen de maniobra del legislador debe ser respetado y debemos considerar que la sanción de la omisión constitucional puede tener lugar. Estos elementos contrarrestan sutilmente las posibles críticas dirigidas hacia la falta de una regla de no regresión.

50. En cuarto lugar, el objetivo de valor constitucional de la vivienda digna carece de especificidad en lo que concierne a las restricciones de otros derechos y libertades, incluyendo el derecho de propiedad. Se trata de limitaciones que forman parte, naturalmente, del acervo del control de proporcionalidad.

51. Globalmente, subrayamos, a modo de cierre, que las condiciones constitucionales estuvieron dadas para que operen mecanismos jurídicos propios al Estado social de derecho. 